\title{
Effects of Fungicide and Herbicide Chemical Exposure on Apis and Non-Apis Bees in Agricultural Landscape
}

\author{
Joseph Belsky and Neelendra K. Joshi* \\ Department of Entomology and Plant Pathology, University of Arkansas, Fayetteville, AR, United States
}

Fungicide and herbicide chemistries are commonly applied in agricultural production systems and other agricultural landscapes during flowering periods, which are concurrent with the timing of bee-dependent pollination services in many plant species. As a result, bees can be exposed to these pesticides while foraging crops and other flowering plants in the landscape where they have been administered. Laboratory and semi-field studies simulating these pesticide exposure scenarios have demonstrated

OPEN ACCESS

Edited by:

Andrew Hursthouse,

University of the West of Scotland,

United Kingdom

Reviewed by:

Xiangke Wang,

North China Electric Power University,

China

Kelly L. Smalling,

United States Geological Survey (USGS), United States

*Correspondence: Neelendra K. Joshi nkjoshi@uark.edu: nkj1005@gmail.com

Specialty section:

This article was submitted to Toxicology, Pollution and the Environment,

a section of the journal

Frontiers in Environmental Science

Received: 25 December 2019 Accepted: 22 May 2020 Published: 28 July 2020

Citation:

Belsky J and Joshi NK (2020) Effects of Fungicide and Herbicide Chemical Exposure on Apis and Non-Apis Bees in Agricultural Landscape. Front. Environ. Sci. 8:81. doi: 10.3389/fenvs.2020.00081 lethal and sub-lethal impacts to both Apis and non-Apis species of domesticated bees. Exposure to fungicides and herbicides has also been attributed to bee genetic and molecular-level changes in some cases. Herbicides can also indirectly impact bees as a result of decreasing weeds and other flowering plants that serve as nutrient resources for foraging bees. We analyze a series of recent studies concerning the toxicity of fungicides and herbicides to Apis and non-Apis bees as a basis for forming our views on key priorities regarding the direction of future research initiatives in this area. Exploring the impacts of agricultural pesticides beyond insecticides to bees is timely given the documented bee declines in the last decade and the resulting widescale interest in identifying the different drivers of these declines among the biological and the ecological scientific communities.

Keywords: fungicides, herbicides, bees, pollination, crop production, fungi, weeds

\section{INTRODUCTION}

Bees are important pollinators of cultivated crops and wild flowering plants, and the ecological services that they provide are integral to plant reproduction and ecosystem foundation. Therefore, bees are a critical variable in the function of agricultural systems used to produce food and fiber crops. Rising awareness of population declines of bees and other invertebrate pollinators over the last decade has dramatically increased the amount of research devoted to this particular area of ecological science, and as a result, several key contributing factors have been identified and reviewed (Maini et al., 2010; Meeus et al., 2018; Belsky and Joshi, 2019). One of these factors is the increased frequency of insecticide applications for plant protection against herbivorous insect pests in commercial agricultural and ornamental crop production. Beyond insecticides, bees are exposed to a diversity of other agricultural chemicals, as demonstrated by Mullin et al. (2010) who found 121 different pesticides and metabolites in beehives and associated hive materials and Hladik et al. (2016) who detected 19 pesticides and degradates in 54 samples of native bees collected from wheat field and grassland land covers. Fungicides (commonly used in agricultural crop production for 
controlling molds and fungal diseases) and herbicides (applied to reduce weeds and other unwanted plants) are among those other chemistries. Determining the impacts of fungicides and herbicides on bees is a new area of major scientific interest given that the global market value (Pesticides Industry Sales Usage, United States Environmental Protection Agency, 2017) and quantity of these chemicals sold and applied (in tonnage) outnumbers insecticides (Eurostat, 2018; Jess et al., 2018). Insecticide toxicity to bees has been extensively investigated over the last 15 years; however, comparatively little is known regarding the impacts of fungicides and herbicides to bees. Since they are often applied in agricultural crop production systems throughout the year, including periods of bloom (Bosch and Blas, 1994; Andert et al., 2016; Zubrod et al., 2019; Heller et al., 2020), Apis and non-Apis bee species can come into contact with these chemicals while actively pollinating. Simulating these scenarios, laboratory, and semi-field studies have demonstrated the impacts of fungicide and herbicide exposure (as both single chemicals and in combination with other pesticides) on lethal and sublethal toxicity to different species of managed bees (Fisher et al., 2017; Heard et al., 2017; Iverson et al., 2019). Several recent studies have also linked physiological changes at the molecular and the genetic levels in bees after exposure to these agricultural chemicals (Jumarie et al., 2017; Mao et al., 2017). Indirect effects on bees include diminished floral resources, resulting from herbicide usage on susceptible weeds and other flowering plants (Bohnenblust et al., 2016; Jacobson et al., 2018).

It is important to note that a small group of commercially bred Apis and non-Apis species comprises the principal agents of agricultural crop pollination. However, the plight of solitary wild bees is crucially important. Diverse pollinator communities are integral for the proper functioning of ecological systems (Ollerton, 2017; Winfree et al., 2018) and have been shown to drive increases in agricultural crop fruit set and yield, especially given the recent declines of domesticated honey bees (Klein et al., 2012; Blitzer et al., 2016; Garibaldi et al., 2016; Woodcock et al., 2019). Currently, less studies on pesticide toxicology to wild solitary bees have been done as a result of their not being regarded as major pollinators combined with the increased difficulty in administering pesticides to these bees (which are often smaller in size) in the laboratory and in the field. Despite this, future research exploring the differences in pesticide impacts among different bee species is warranted, given the discrepancies in the results of existing studies. Conflicting findings such as those suggesting differences in pesticide toxicology among bee species (Biddinger et al., 2013; Sgolastra et al., 2017) and those that do not (Spurgeon et al., 2016; Heard et al., 2017) must be further addressed, especially with regard to fungicide and herbicide chemistries. Although most of this work has and will continue to focus on the grouping of commercialized Apis and nonApis species, taking this approach at least begins to expand into solitary bees. We address this subject along with disagreement in the discussion as to whether honey bees can serve as a surrogate for non-Apis species in pesticide toxicology testing.

Here we discuss recent studies that demonstrate the toxicity of fungicides and herbicides to commercialized Apis and non-Apis bee species. We also discuss current knowledge gaps and present our views on future research areas and regulatory framework needs to appropriately assess the risks of bee exposure to fungicide and herbicide chemistries.

\section{FUNGICIDE AND HERBICIDE CHEMISTRIES AND MODES OF ACTION}

Fungicides are classified into several families. Sterol biosynthesis inhibitors (SBI) and demethylation inhibitors (DMI) inhibit the cytochrome P450 monooxygenase-dependent step in fungal egosterol production and cell wall synthesis (Kuck et al., 2012; Casida and Bryant, 2017; Zubrod et al., 2019). Respiratory chain succinate dehydrogenase inhibitors of complex II impede respiratory chain succinate dehydrogenase (Angelini et al., 2014), while respiratory chain strobilurin-type quinone outside-site of complex III inhibitors inhibit mitochondrial respiration by interfering with proper electron transport from cytochrome b to cytochrome $c_{1}$ (Bartlett et al., 2002; Zubrod et al., 2019). Chlorothalonil is a chloronitrile fungicide that functions through multiple modes of action (Zubrod et al., 2019).

Herbicides are classified by their mode of action. 4Hydroxyphenylpyruvate dioxygenase inhibitors impair carotenoid biosynthesis, causing plant bleaching and subsequent death (Hawkes, 2012), while protoporphorinogen-IX-oxidase inhibitors facilitate the peroxidization of fatty acid unsaturated bonds within cell membranes (Theodoridis et al., 2012). Acetyl CoA carboxylase inhibitors prevent the normal metabolism of fatty acids (Bretschneider et al., 2012; Wenger et al., 2012). Cellulose biosynthesis inhibitors prevent the formation of crystalline cellulose fibers that are essential for the stability of plant cell walls (Dietrich and Laber, 2012). Acetolactate synthase inhibitors prevent the biosynthesis of branched amino acids, leading to cell division impairment (Jeschke, 2015). Auxin mimics function by mimicking the auxin hormone necessary for plant growth (Walsh and Schmitzer, 2012; Jeschke, 2015).

\section{TOXICITY OF FUNGICIDES TO DIFFERENT SPECIES OF BEES}

\section{Apis Bees}

Several recent studies have demonstrated the toxicity of fieldrealistic fungicide exposure to a variety of honey bee adult and larval health endpoints. The toxicities of both single active ingredient fungicides and the synergistic combinations of fungicides + other agricultural chemicals to honey bees have been demonstrated. Fungicide contact and oral $\mathrm{LD}_{50}$ values and toxicity assessment to honey bees are presented by Stoner and Eitzer (2013) and Ladurner et al. (2005) and may vary across different compounds. For instance, upon investigating the foliar spray toxicity of formulated fungicides commonly used in almond production to honey bees (Apis mellifera), Fisher et al. (2017) showed that both exposure to Iprodione 2SE Select ${ }^{\circledR}$ (iprodione) alone and spray-tank mixes with either Pristine ${ }^{\circledR}$ (boscalid and pyraclostrobin) or Quadris ${ }^{\circledR}$ (azoxystrobin) significantly decreased forager survival. Using 
technical-grade chemicals, Johnson et al. (2013) determined that four SBI fungicides increased the acute toxicity of the acaricide tau-fluvalinate to honey bee adult workers in a dose-dependent manner. This synergism is attributed to the inhibition of cytochrome P450 monooxygenase enzyme activity. An increased in the acute toxicity of the acaricides coumaphos and fenpyroximate was observed when honey bees were also exposed to the SBI fungicide prochloraz, while pre-treatment with the acaricide amitraz increased the acute toxicity of three other acaricides that are cytochrome P450-detoxified. Exposure to fungicides may also result in increased susceptibility to other pesticides, mainly insecticides. For instance, clothianidin and thiamethoxam became significantly more toxic to honey bee workers exposed to boscalid-contaminated pollen in maize fields by measuring of decreased $\mathrm{LD}_{50}$ levels (Tsvetkov et al., 2017). Feeding honey bees with syrup contaminated with either copper oxychloride for $108 \mathrm{~h}$ and thiram for $168 \mathrm{~h}$, Migdal et al. (2018) determined a daily fungicide intake of 4.75 and $16.78 \mathrm{~mm}^{3} / \mathrm{bee}$, respectively. The daily mortality was 35.15 bees/cage for copper oxychloride and 5.17 bees/cage for thiram.

Several studies have also analyzed the impact of fungicides on honey bees at the molecular level. For example, adult consumption of flavonol quercetin mixed with the triazole fungicide myclobutanil resulted in the down-regulation of five of the six mitochondrion nuclear genes (Mao et al., 2017). This study also concluded that bees ingesting $0.25 \mathrm{mM}$ quercetin combined with 5 ppm myclobutanil displayed depressed thoracic ATP levels compared to bees ingesting quercetin only. Exposing different developmental life stages of honey bees to the fungicide prochloraz and the acaricide coumaphos individually and in combination, Cizelj et al. (2016) documented differentiated molecular-level immune responses in brood versus adults. Specifically, by examining the expression of 17 immune-related genes by quantitative RT-PCR, gene downregulation was found in prepupae, while gene upregulation for most genes was found in adults following all treatments. In adult bees, prochloraz + coumaphos exposure resulted in the upregulation of the antimicrobial genes abaecin and defensin-1. In a similar study, Christen et al. (2019) observed the effect of orally exposing honey bees to the fungicides azoxystrobin, chlorothanolin, and folpet over 24, 48, and $72 \mathrm{~h}$ on gene transcription within their brains. They found that while azoxystrobin and folpet induced minor changes, including the downregulation of $h b g-3$ and the induction of $n d u f b-7$, respectively, chlorothanolin resulted in the major transcriptional down-regulation of genes related to oxidative phosphorylation and metabolism. In particular, chlorothanolin downregulated genes that include cyp9q1, cyp9q2, cyp9q3, acetylcholine receptors alpha 1, hbg-3, and ilp-1, all of which influence honey bee hormonal regulation and behavioral transition, such as nurse bees transitioning into foragers. Moreover, chlorothanolin exposure resulted in the largest overall impact on the transcriptional abundance of genes linked to honey bee energy production, metabolism, and the endocrine system, where the strongest effect was observed in the early spring as opposed to the early summer. Orally exposing Africanized honey bees to low concentrations ( 9 and $18 \mathrm{ppb}$ ) of the strobilurin fungicide picoxystrobin continuously at 24-96 h, Batista et al. (2020) conducted a Malpighian tubule and midgut histopathological diagnosis and labeling of resulting cell death. While their results did not show any impact on the Malpighian tubules, data of the histopathological effects on the midgut were observed for bees consuming both concentrations. Indication of cell death and other morphological changes were recorded beginning at $24 \mathrm{~h}$ following initial exposure, thereby indicating that picoxystrobin exposure may compromise the ability of the honey bee midgut to absorb nutrients at a long term, which may result in malnutrition and impaired performance. In disagreement with these results, Decio et al. (2019) show that honey bee exposure to thiamethoxam + the fungicide carbendazim does not (a) increase the acute toxicity of thiamethoxam and (b) induce alternative splicing of the mRNAs examined. Specifically, they investigated three genes that are important in honey bee neuronal function: the stress sensor gene $X$ box binding protein-1, the Down Syndrome Cell Adhesion Molecule gene, and the embryonic lethal/abnormal visual system gene. Therefore, they conclude that no honey bee cellular response is triggered as a result of exposure to this fungicide in the presence of thiamethoxam.

Fungicides may affect larval development or may alter the physiological developmental in bees. Larval oral consumption of technical-grade propiconazole or iprodione + chlorantraniliprole significantly reduced adult eclosion compared to a larval dietary intake of only chlorantraniliprole (Wade et al., 2019). Similarly, larvae fed with iprodione + methoxyfenozide or diflubenzuron alone or as a mixture with any of the tested fungicides reduced adult emergence compared to controls fed with acetone solvents only. Examining synergism between the formulated Pristine ${ }^{(B)}$ and the spray adjuvant Break-Thru ${ }^{\circledR}$ (polyether-polymethylsiloxanecopolymer) on honey bee queen rearing success, Johnson and Percel (2013) determined that neither chemical nor their combination had a significant effect on immature queen survival. However, low levels of pyraclostrobin (50 ppb), but not boscalid, were found in royal jelly secreted by nurse bees feeding on treated pollen. Similarly, in feeding honey bee larvae different doses of technical-grade boscalid, Simon-Delso et al. (2017) quantified the safety levels of $741 \mathrm{ppm}$ in pollen and $27 \mathrm{ppm}$ in nectar, which are higher than $1 \mathrm{ppm}$ isolated in pollen (Johnson et al., 2010; Stoner and Eitzer, 2013) and 1.43 ppm isolated in nectar (Wallner, 2010).

\section{Non-Apis Bees (Bombus and Solitary Species)}

Fungicides have been also demonstrated to impose toxicity to non-Apis bees by impairing colony performance, output and behavior for social species, and reproductive capacity and behavior for solitary species. For instance, synergized mortality following exposure to combinations of fungicides + insecticides and molecular-level impacts of fungicides on bumble bee flight have also been reported. Feeding Bombus terrestris adults with sugar syrup laced with the ergosterol biosynthesis inhibitor (EBI) fungicide imazalil + an insecticide, Raimets et al. (2018) 
demonstrated that imazalil synergized the acute toxicity of fipronil, cypermethrin, and thiamethoxam. Therefore, the impact that EBI has in inhibiting P450 detoxification on bumble bees is different for individual pesticide chemistries. Conversely, feeding queenless $B$. terrestris microcolonies with pollen laced with captan at a field-realistic rate $(10 \mathrm{mg} / \mathrm{kg})$ had no effect on colony or individual worker longevity, consumption of pollen or sugar syrup, and normal larval development for all castes (Malone et al., 2007). Upon exposing queenless microcolonies of $B$. terrestris to honey water and pollen paste containing field-realistic average $(23 \mathrm{mg} / \mathrm{kg})$ or maximum $(230 \mathrm{mg} / \mathrm{kg})$ concentrations of the DMI fungicide propiconazole for 28 days, Elston et al. (2013) concluded that both concentrations reduced honey water consumption, while the smaller dose also decreased the quantity of wax cells produced. Separately, Bernauer et al. (2015) exposed five Bombus impatiens colonies to flowers treated with chlorothalonil at a field-realistic rate $(20 \mathrm{~g} / \mathrm{L})$ over the course of 1 month. The treated colonies produced less than one-third as many workers, contained less than $50 \%$ of bee biomass, and were queened by mothers with $50 \%$ of body mass compared to controls. Considering the findings of these researchers, it is important to characterize the mode of action of fungicides in bees. In a recent study, exploring the sensitivity of $B$. terrestris flight muscle mitochondrion to 16 fungicides, Syromyatnikov et al. (2017) determined disconnected respiration following exposure to diniconazole and fludioxonil and inhibited respiration following exposure to dithianon and difenoconazole. These researchers found the inhibition of electron transport at complex I and glycerol-3-phosphate dehydrogenase by difenoconazole exposure. Diathianon also inhibits succinate dehydrogenase and the oxidation of both nicotinamide adenine dinucleotide substrates and glycerol-3phosphate while not impacting complex I like difenoconazole (Syromyatnikov et al., 2017).

Exposure to fungicides may also result in increased susceptibility to other pesticides, mainly insecticides. An experimental design comparing the impact of oral consumption of insecticide + fungicide mixtures on three bee species (A. mellifera, B. terrestris, and Osmia bicornis) found a small but maintained increase in clothianidin toxicity when combined with propiconazole, which was especially pronounced for the two non-Apis species with an almost three-fold increase for O. bicornis (Robinson et al., 2017). In a similar study, contact exposure of insecticides + fungicides, approximating $\mathrm{LD}_{20}$ values and maximum sublethal levels, respectively, resulted in synergistic toxicity to B. impatiens workers (Iverson et al., 2019). Specifically, a synergistic interaction was noted for the triazole SBI fungicide difenoconazole when mixed with the pyrethroid bifenthrin, resulting in a maximum synergy ratio of 1.48. A separate synergistic interaction was observed for mixtures of the triazole fungicide myclobutanil with both bifenthrin and thiamethoxam, resulting in maximum synergy ratios of 11.0 and 2.38 , respectively.

Although less examined, the toxicity of fungicides to commercially available solitary bees has also been assessed. Specific findings show synergisms arising from exposure to fungicide + insecticide combinations, differential toxicities of fungicides to solitary bees compared to honey bees, and direct impacts of fungicides on solitary bee female nest construction and provisioning. Feeding O. bicornis females with a sugar solution containing either propiconazole or clothianidin, or a combined mixture, Sgolastra et al. (2018) noted a significantly lower feeding for the combined mixture, which decreased as emergence time increased. A significant synergistic interaction was determined for clothianidin + propiconazole on day 4 of treatment by means of a survival curve analysis. Post-exposure assessment at 3 days also revealed a significant synergistic interaction for the combined mixture, where $O$. bicornis exposed to this mixture had shorter oocytes compared to bees in all other treatments. Similarly, comparing the toxicity of these same chemicals and their combination to three bee species, Sgolastra et al. (2017) identified significant synergism by the measure of mortality for all bee species exposed to clothianidin + propiconazole. However, this synergism only lasted for the duration of the experiment (96 h) for O. bicornis. Comparing the exposure of Osmia lignaria and $A$. mellifera to five fungicides in cage studies, Ladurner et al. (2005) determined that the oral ingestion of propiconazole was acutely toxic to both species, while oral and contact exposure to captan was chronically toxic to O. lignaria only by severely impacting survival between $72 \mathrm{~h}$ and 7 days after exposure. In another study, Biddinger et al. (2013) showed synergistic toxicity to Osmia cornifrons when the fungicide fenbuconazole was mixed with commonly used neonicotinoid insecticides.

Comparing fungicide spray toxicity to O. lignaria and Megachile rotundata in semi-field cage studies, Artz and Pitts-Singer (2015) document O. lignaria exposure to technicalgrade iprodione, and a premix fungicide with boscalid pyraclostrobin active ingredients and the non-ionic spray adjuvant (polyethoxylated non-ylphenol) negatively affected female nest recognition ability. Similarly, $M$. rotundata female nest recognition was impacted following exposure to a treatment containing fungicide premix (boscalid and pyraclostrobin) and polyethoxylated non-ylphenol adjuvant. Conversely, in a separate semi-field cage study, Ladurner et al. (2008) concluded that $O$. lignaria foraging and nesting behavior were unaffected when sprayed with one of the fungicides iprodione, propiconazole, benomyl, and captan.

\section{EFFECTS OF HERBICIDE EXPOSURE TO BEES}

\section{Apis Bees}

Herbicide exposure has been found to negatively impact different aspects of honey bee life, including drone sperm count, adult worker survival, and larval midgut composition. Impaired honey bee metabolic activity has also been demonstrated following exposure to single herbicides and or combinations of herbicides + metal mixtures. Testing the impact of glyphosate on honey bee drone spermatozoa, Hoopman et al. (2018) determined an $\mathrm{LD}_{50}$ of $0.31 \mathrm{mg} / \mathrm{ml}$, where the number of dead spermatozoa significantly increased with both exposure time and glyphosate concentration. Honey bee consumption of sugar syrup laced with bentazone and metamitron over a duration 
of $168 \mathrm{~h}$ resulted in a daily herbicide intake of 16.16 and $13.87 \mathrm{~mm}^{3}$ /bee, respectively (Migdał et al., 2018). Daily mortality of 3.21 bees/cage and increased aggression were noted for bentazone, while metamitron exposure leads to a daily mortality of 13.00 bees/cage and low to moderate levels of increased bee aggression and mobility. Chronic in vitro larval exposure to glyphosate traces $(1.25-5.0 \mathrm{mg} / \mathrm{L}$ of food) resulted in reduced brood weight and delayed molting (Vázquez et al., 2018). The authors acknowledge that while this experimental design does not account for nurse-bee feeding of brood, it does enable the researchers to control the glyphosate dose in the larval food and hence have it tested. Similarly, larval consumption of technicalgrade glyphosate revealed significantly decreased survival (4 and $20 \mathrm{mg} / \mathrm{L}$ doses) and larval weight (0.08 and $4 \mathrm{mg} / \mathrm{L}$ doses $)$ (Dai et al., 2018).

Several projects have also demonstrated the impacts of herbicides on impairing honey bee learning, sensory abilities, and navigation. For example, in analyzing the effects of chronic exposure to field-realistic concentrations of imidacloprid + glyphosate on honey learning, Mengoni Goñalons and Farina (2018) show reductions in sucrose responsiveness and impaired olfactory learning. Larva reared on food contaminated with glyphosate ate less, thereby further supporting the results of Dai et al. (2018) and Vázquez et al. (2018). Testing whether sub-lethal glyphosate concentrations affect honey bee homeward foraging and navigation, Balbuena et al. (2015) showed that bees fed sugar syrup laced with $10 \mathrm{mg} / \mathrm{L}$ ( $0.500 \mu \mathrm{g}$ per bee) at a feeder spent more time flying home compared to controls or bees fed lower concentrations of 2.5 and $5 \mathrm{mg} / \mathrm{L}$ ( 0.125 and $0.250 \mu \mathrm{g}$ per bee). Honey bees fed sugar syrup with the higher glyphosate concentration also performed more indirect flights; following a second release, the proportion of accurate homeward flights increased for controls, but not for treated bees. This result demonstrates that oral consumption of field-realistic doses of glyphosate (simulating that found in nectar) can impair the ability for honey bee foragers to learn a navigational task such as flying back to their hive.

An analysis of larval midgut bacteria composition demonstrated a significant decrease in beta diversity following an uptake of $20 \mathrm{mg} / \mathrm{L}$ glyphosate compared to controls (Dai et al., 2018). Confirming these results, Vázquez et al. (2018) also found that immune and detoxifying gene transcription within larval guts was variable among the numerous colonies studied following their exposure to glyphosate. Exposing adult bees to syrup contaminated with $0.12 \mathrm{mg} / \mathrm{L}$ glyphosate, atrazine, and $0.03 \mathrm{mg} / \mathrm{L}$ cadmium alone or in combination revealed that consuming herbicide + metal mixtures decreased the levels of alpha- and beta-carotene (Jumarie et al., 2017). Metabolically, herbicide + metal mixtures were indicative of impacting processes downstream of retinaldehyde formation and vitamin A metabolism and significantly increased thiobarbituric acid reactive substances (TBARS) levels compared to controls. Similarly, honey bee's consumption of sugar solution over 10 days significantly decreased $\beta$-carotene and all-trans-retinol $(a t-\mathrm{ROH})$ when spiked with atrazine and increased lutein and at-ROH when spiked with metolachlor (Helmer et al., 2015). Glyphosate-spiked solutions significantly decreased $\beta$-carotene as doses increased and significantly increased the mean value of $\alpha$-tocopherol at the dose of $1.25 \mathrm{ng} / \mathrm{bee}$. Metolachlor ingestion of $20 \mathrm{ng} /$ bee significantly reduced the TBARS levels compared to controls, oral uptake of glyphosate significantly decreased the protein levels as doses increased, and the highest dose of atrazine ( $5 \mathrm{ng} / \mathrm{bee}$ ) significantly altered bee mass compared to controls. Similarly, Motta et al. (2018) show that honey bees exposed to field-realistic concentrations of glyphosate have decreased abundances of dominant species of the gut microbiota. In this study, young worker bees exposed to glyphosate, after being exposed to the pathogen Serratia marcescens, displayed higher levels of mortality. Moreover, this study confirmed that different species of honey bee gut microbiota responded differently in their susceptibility to glyphosate; this difference was largely driven by their possession of either 5-enolpyruvylshikimate3-phosphate synthase (ESPS) class I (glyphosate-sensitive) or class II (glyphosate-insensitive). Subsequent in vitro experiments cloning the ESPS gene from honey bee gut bacteria into Escherichia coli further confirmed this difference - namely, reductions in most strains of the honey bee bacterial gut species Snodgrassella alvi were a consistent outcome. However, it was also found that some $S$. alvi strains are tolerant of glyphosate, indicating that they have an alternative resistance mechanism, warranting further investigation. In contrast, Decio et al. (2019) show that honey bee exposure to thiamethoxam + glyphosate does not (a) increase the acute toxicity of thiamethoxam and (b) induce the alternative splicing of the mRNAs examined. Specifically, they investigated three genes that are important in honey bee neuronal function: the stress sensor gene $X$ box binding protein-1, the Down Syndrome Cell Adhesion Molecule gene, and the embryonic lethal/abnormal visual system gene, and they concluded that no honey bee cellular response is triggered as a result of exposure to glyphosate in the presence of thiamethoxam.

\section{Non-Apis Bees (Bombus and Solitary Species)}

In the recent past, the different toxicity of herbicides to non-Apis bee species, compared to honey bees, has also been determined. Stingless bee species oral ingestion resulted in paraquat inducing higher mortality for Tetragonisca fiebrigi and nicosulfuron inducing higher mortality in Tetragonisca angustula (Fermino et al., 2011). Increased superoxide dismutase isoenzyme activity was observed in both species after exposure to paraquat and is believed to be physiologically related to paraquat detoxification. A separate study observing the effect of oral and contact exposure to glyphosate, 2,4-D, picloram, and glyphosate $+2,4-\mathrm{D}$ on the survival of Melipona scutellaris showed no decrease in longevity, following the application of $50 \%$ of the recommended field dose for all compounds (Nocelli et al., 2019). However, decreased $M$. scutellaris longevity was observed following a contact topical application of $100 \%$ of the recommended field dose for glyphosate $+2,4-\mathrm{D}$. Oral exposure of both $100 \%$ and twice the recommended field dose reduced the longevity for all compounds except for 2,4-D at twice the recommended field dose. Interestingly though, when separately evaluating the impact 
of these herbicides on M. scutellaris temperature control and colony weight in semi-field conditions, Nocelli et al. (2019) found no differences between control and exposure treatments.

A comparative toxicity study of 2,4-dichlorophenoxyacetic acid to three bee species over 10 days of ad libitum feeding found the same $\mathrm{LC}_{50}$ for $A$. mellifera and B. terrestris $(>900 \mathrm{mg} / \mathrm{L})$ and a higher $\mathrm{LC}_{50}$ for $O$. bicornis $(>1,437.5 \mathrm{mg} / \mathrm{L}$ ) (Heard et al., 2017). Although the premise of this study is that honey bees can serve as a surrogate for non-Apis bees, this discrepancy supports a separate assessment of individual bee species. Exposing A. mellifera and Hypotrigona ruspolii to plant material sprayed with $1 \times$ and $2 \times$ the label-recommended dose of Sunphosate $360 \mathrm{SL}^{\circledR}$ (360 g/L glyphosate in $480 \mathrm{~g} / \mathrm{L}$ isopropylamine salt) significantly impacted bee mortality as measured at $24 \mathrm{~h}$ after the treatment (Abraham et al., 2018). Similarly, significantly higher mortality was recorded at $24 \mathrm{~h}$ for $H$. ruspolii contacting dried filter paper drenched with the recommended dose of Sunphosate $360 \mathrm{SL}^{\circledR}$ - namely, these studies bolster support for the notion that Apis species cannot serve as a surrogate for nonApis species in assessing the impacts of herbicide toxicity, as has been previously shown for insecticides (Biddinger et al., 2013; Sgolastra et al., 2017). As a result, they strongly support the need for future research that specifically investigates the impacts of herbicides on the non-Apis species in question.

\section{Indirect Effects of Herbicide Use: Decreasing Floral Resources in Farmscape}

Multiple interactions between bees, weed abundance, and pollination have been identified in the recent past. For example, weeds are a quantitative limiting resource for honey bees in between massive pollination events and a qualitative limiting resource for wild bees that are specialist foragers (Bretagnolle and Gaba, 2015). Changes in New Hampshire bumble bee species richness have been linked to habitat degradation, agricultural practices, and urban development which reduce floral resources (Jacobson et al., 2018). Specifically, Bombus vagans has been ecologically replaced by the generalist $B$. impatiens, while the range of Bombus terricola has shifted to higher elevations in more northern latitudes. Examining genetically modified herbicidetolerant canola and adjacent wildflower strips, O'Brien and Arathi (2018) concluded that these plants provide wild bees refugia habitats by calculating a higher species diversity index for a wildflower plot compared to two canola plots.

Evaluating synthetic-auxin herbicides, Bohnenblust et al. (2016) show that dicamba application, at doses simulating particle drift, delayed and reduced plant flower production and resulted in diminished pollinator visitation. Surveying herbicide presence in native bee tissue from samples collected in two ecologically distinct habitats, Hladik et al. (2016) detected maximum concentrations of atrazine $(99 \mathrm{ng} / \mathrm{g})$ and metolachlor (13 ng/g) in 19 and $9 \%$ of samples, respectively. County peak application levels for the period 2008-2012 were 28,000 kg for atrazine and 22,000 kg for metolachlor (Baker and Stone, 2013). Assessing honey bee pollen pesticide contamination over a 16-week period, Long and Krupke (2016) note that herbicides and fungicides comprised the most common pesticides. In non-agricultural areas, $83.3 \%$ of pollen samples contained metolachlor; adjacent to untreated maize, 75 and $54 \%$ of pollen samples contained metolachlor and atrazine, respectively, and adjacent to treated maize, $34-87.5 \%$ of pollen samples contained metolachlor, atrazine, and acetochlor.

\section{CONCLUSION AND RECOMMENDATIONS}

Pesticide toxicology studies on bees have primarily emphasized insecticides, given their specific design to kill insect species. As a result, a large quantity of data detailing if and how insecticides impact bee survival, at acute exposure, and behavior and normal function, at chronic exposure and sub-lethal doses, has been generated. However, in comparison, fairly little is known regarding the toxicity of other commonly used agricultural chemicals (namely, fungicides and herbicides) to bees. Moreover, the discovery of multiple dimensions of fungicide and herbicide toxicity to Apis and non-Apis species (as detailed in this review) elevates their likelihood of being potentially harmful to bees. For fungicides and herbicides, cases of direct acute mortality and sub-lethal impairment of normal biological behavior have been documented. Application of fungicides (unlike many insecticides) is widely permitted during crop bloom when bees actively pollinate, thereby exacerbating this situation for fungicides. Beyond directly imposing toxicity and impairment of normal functioning to bees, herbicides can also indirectly harm bees by decreasing the available forage resources. Weeds and other non-crop flowering plants provide essential food resources for bees. However, many of these naturally occurring flowering plants commonly foraged by bees are not genetically modified to tolerate herbicides. As a result, herbicide application often kills these flowering plants. Therefore, the importance of future research studies that build upon the results of current studies by continuing to investigate how exposure to these agricultural chemicals affects bees is highly elevated.

From our preliminary analysis of the published data on fungicide and herbicide toxicity to bees, we have identified several knowledge gaps that should be addressed in future work. First off, we explore how the plight of commercialized non-Apis species and specifically solitary bees should be addressed going forward. Currently, most research have focused on honey bees, which is reasonable given their widescale commercialization and usage in pollination events. However, for insecticides, it has been demonstrated that Apis and non-Apis species can react differently (Biddinger et al., 2013; Belsky, 2018), which may in part be explained by differences in how these bee species interact with their environmental surroundings where these insecticides are applied (Boyle et al., 2019; Hinarejos et al., 2019). Conversely, honey bees have been demonstrated to be suitable surrogates for non-Apis species in tier I insecticide assessments as in Thompson and Pamminger (2019). Although some work have investigated the impacts of fungicides and herbicides on non-Apis species, future studies should directly compare their acute and sublethal impacts on Apis and non-Apis species simultaneously in 
both lab and field settings. Additionally, extrapolation on how differences in environmental interaction between Apis and nonApis species influence their exposure to fungicide and herbicide chemistries and, hence, resulting susceptibility or resistance is needed. It is important to note that most of these studies will address a handful of non-Apis species that are commercially bred for pollination services. Regarding the majority of solitary species remaining, although they are not utilized for commercial pollination, their plight is equally as important. These species are often specialist pollinators that only pollinate a small group of plants that flower in synchrony with their pupal eclosion (Wcislo and Cane, 1996). Therefore, work investigating how usage of fungicides and herbicides in agricultural environments indirectly impacts these bees by means of killing the plants they pollinate is a future direction for research efforts. Also, since most solitary bees construct their nests in the soil (Cane, 2001), an assessment of how they encounter fungicide and herbicide chemistries on these substrates would be useful and builds upon the findings of Boyle et al. (2019) and Hinarejos et al. (2019). Additionally, several non-commercialized bees such as Xylocopa, Exomalopsis, Centris, Oxaea, and many Halictidae species have been documented to contribute to eggplant pollination (Patricio et al., 2012), while Halictidae and Andrenidae species were found to be the predominant pollinators of blueberries (Tuell and Isaacs, 2009). New projects can explore how fungicide and herbicide application in agricultural crop production systems at least partially pollinated by non-commercialized bee species impacts their abundance and pollination performance.

Other knowledge gaps in our current understanding of how fungicide and herbicide chemistries impact bees relate to aspects of experimental design. While most studies have examined acute toxicity in a laboratory setting and a few have brought this initial work into field settings, more field work is needed. Specifically, semi-field studies exposing bees in tunnels or greenhouses and true field studies exposing bees in their natural environments will aid in our understanding of how bees encounter fungicides and herbicides through interacting with their environmental surroundings. Although some work have addressed chronic toxicity by feeding bees fungicide- or herbicide-laced syrup for multiple days and sub-lethal toxicity through mapping changes in bee functioning and behavior following exposure, this is only the beginning. Pinpointing the duration of exposure for bee chronic toxicity onset and determining precisely when sublethal exposure translates into bee behavioral changes will aid pesticide applicators in making improved decisions regarding the timing of fungicide and herbicide administration. Using these data, pesticide applicators will be able to incorporate procedures to protect non-target bees from these agricultural chemicals into their application protocols. A few studies have explored how fungicides and herbicides impact honey bee brood (and specifically larvae) (Dai et al., 2018; Vázquez et al., 2018). More studies in this direction that expand into non-Apis brood (probably starting with the domesticated Bombus species) are warranted. Another aspect that has briefly been investigated are the impacts of fungicides and herbicides on bees at the molecular and the genomic levels. Specifically, future work should build upon results such as those of Dai et al. (2018) and Motta et al. (2018) by mapping physiological changes at the molecular genomic level in more precise detail following contact with fungicides, herbicides, and their combination with insecticides or diseases. It is plausible that exposure to these chemicals alters normal gene expression and microbial composition (as has been demonstrated in several studies), which inhibits the ability for bees to detoxify an insecticide or combat a malady.

Findings of synergism arising from a combined contact with insecticides + fungicides or herbicides suggest that exposure to these chemicals in combination might in part instigate their observed hazard to bees. Therefore, the degree to which the potency of fungicides and herbicides to bees results from interactions with other stressors in their environments should be extrapolated in a future work. Most projects investigating herbicides have focused on glyphosate, which is a great start, however, there are a multitude of other herbicide chemistries that are commonly used to control weeds in agricultural settings. Therefore, future research endeavors should prioritize an examination of the toxicity of these different herbicide chemistries to bees.

Building upon our current data regarding insecticide toxicity to bees, the next wave of pesticide research on bees should strongly incorporate fungicides and herbicides. This work is timely given the widescale usage of fungicide and herbicide chemistries in agriculture by measure of market value (Pesticides Industry Sales Usage. United States Environmental Protection Agency, 2017). Moreover, the quantity of these chemicals sold and applied (in tonnage) outnumbers insecticides (Eurostat, 2018; Jess et al., 2018). Since fungicide and herbicide chemistries are commonly applied in environments where domesticated bees are placed for pollination services or that native bees inhabit, analyzing their impact on these organisms is of rising importance. Future research efforts moving in this direction will further illuminate our understanding (as scientists, growers, beekeepers, and pesticide applicators) of the consequences of bee interactions with the full spectrum of agricultural chemicals. Obtaining and utilizing this information will enable our ability to cohesively unify in modifying fungicide and herbicide application protocols to ensure that they do not impact non-target pollinating bees by means of appropriately reflecting the most recent data findings.

\section{AUTHOR CONTRIBUTIONS}

JB and NJ conceived the plan of this study. JB prepared the draft with inputs from NJ. Both authors contributed to the article and approved the submitted version.

\section{ACKNOWLEDGMENTS}

We are thankful to the USDA-NIFA (Project \# ARK02527) and the UA System Division of Agriculture for support. Any opinions, findings, conclusions, or recommendations expressed in this publication are those of the authors and do not necessarily reflect the view of the US Department of Agriculture. 


\section{REFERENCES}

Abraham, J., Benhotons, G. S., Krampah, I., Tagba, J., Amissah, C., and Abraham, J. D. (2018). Commercially formulated glyphosate can kill non-target pollinator bees under laboratory conditions. Entomol. Exp. Appl. 166, 695-702. doi: 10. 1111/eea.12694

Andert, S., Bürger, J., Stein, S., and Gerowitt, B. (2016). The influence of crop sequence on fungicide and herbicide use intensities in North German arable farming. Eur. J. Agron. 77, 81-89. doi: 10.1016/j.eja.2016.04.003

Angelini, R. M., Masiello, M., Rotolo, C., Pollastro, S., and Faretra, F. (2014). Molecular characterisation and detection of resistance to succinate dehydrogenase inhibitor fungicides in Botryotinia fuckeliana (Botrytis cinerea). Pest. Manag. Sci. 70, 1884-1893. doi: 10.1002/ps.3748

Artz, D. R., and Pitts-Singer, T. L. (2015). Effects of fungicide and adjuvant sprays on nesting behavior in two managed solitary bees. Osmia lignaria and Megachile rotundata. PLoS One 10:e0135688. doi: 10.1371/journal.pone.0135688

Baker, N. T., and Stone, W. W. (2013). Estimated Annual Agricultural Pesticide use for Counties of the Conterminous United States. Resto, VA: U.S. Geological Survey, 2008-2012.

Balbuena, M. S., Tison, L., Hahn, M.-L., Greggers, U., Menzel, R., and Farina, W. M. (2015). Effects of sublethal doses of glyphosate on honeybee navigation. J. Exp. Biol. 218, 2799-2805. doi: 10.1242/jeb.117291

Bartlett, D. W., Clough, J. M., Godwin, J. R., Hall, A. A., Hamer, M., and ParrDobrzanski, B. (2002). The strobilurin fungicides. Pest Manag. Sci. 58, 649-662.

Batista, A. C., da Costa Domingues, C. E., Costa, M. J., and Mathias Silva-Zacarin, E. C. (2020). Is a strobilurin fungicide capable of inducing histopathological effects on the midgut and Malpighian tubules of honey bees? J. Apic. Res. doi: 10.1080/00218839.2020.1724678

Belsky, J. E. (2018). Toxicity of Formulated Insecticide Mixtures to Apis and Non-Apis Bees. Available online at: https://search.proquest.com/openview/ 5ee204690458b1f044ce08b688c0c732/1.pdf?pq-origsite $=$ gscholar\&cbl $=$ $18750 \&$ diss $=y$ (accessed February 24, 2020).

Belsky, J., and Joshi, N. K. (2019). Impact of biotic and abiotic stressors on managed and feral bees. Insects 10, 1-42. doi: 10.3390/insects10080233

Bernauer, O., Gaines-Day, H., and Steffan, S. (2015). Colonies of bumble bees (Bombus impatiens) produce fewer workers. less bee biomass, and have smaller mother queens following fungicide exposure. Insects 6, 478-488. doi: 10.3390/ insects 6020478

Biddinger, D. J., Robertson, J. L., Mullin, C., Frazier, J., Ashcraft, S. A., Rajotte, E. G., et al. (2013). Comparative toxicities and synergism of apple orchard pesticides to Apis mellifera (L.) and Osmia cornifrons (Radoszkowski). PLoS One 8:e72587. doi: 10.1371/journal.pone.0072587

Blitzer, E. J., Gibbs, J., Park, M. G., and Danforth, B. N. (2016). Pollination services for apple are dependent on diverse wild bee communities. Agric. Ecosyst. Environ. 221, 1-7. doi: 10.1016/j.agee.2016.01.004

Bohnenblust, E. W., Vaudo, A. D., Egan, J. F., Mortensen, D. A., and Tooker, J. F. (2016). Effects of the herbicide dicamba on nontarget plants and pollinator visitation. Environ. Toxicol. Chem. 35, 144-151. doi: 10.1002/etc. 3169

Bosch, J., and Blas, M. (1994). Foraging behavior and pollinating Efficiency of Osmia cornuta and Apis mellifera on Almond (Hymenoptera. Megachilidae and I). Appl. Entomol. Zool. 29, 1-9. doi: 10.1303/aez.29.1

Boyle, N. K., Pitts-Singer, T. L., Abbott, J., Alix, A., Cox-Foster, D. L., Hinarejos, S., et al. (2019). Workshop on pesticide exposure assessment paradigm for non-apis bees: foundation and summaries. Environ. Entomol. 48, 4-11. doi: 10.1093/ee/nvy103

Bretagnolle, V., and Gaba, S. (2015). Weeds for bees? A review. Agron. Sustain. Dev. 35, 891-909. doi: 10.1007/s13593-015-0302-5

Bretschneider, T., Fischer, R., and Nauen, R. (2012). "Inhibitors of lipid synthesis: acetyl-CoA-carboxylase inhibitors," in Modern Crop Protection Compounds, eds W. Kramer, U. Schirmer, P. Jeschke, and M. Witschel (Weinheim: Wiley VCH), 1108-1126.

Cane, J. H. (2001). Habitat Fragmentation and native bees: a premature verdict? Conserv. Ecol. 5:3. doi: 10.5751/ES-00265-050103

Casida, J. E., and Bryant, R. J. (2017). The ABCs of pesticide toxicology: amounts, biology, and chemistry. Toxicol. Res. 6, 755-763. doi: 10.1039/C7TX00198C

Christen, V., Krebs, J., and Fent, K. (2019). Fungicides chlorothanolin, azoxystrobin and folpet induce transcriptional alterations in genes encoding enzymes involved in oxidative phosphorylation and metabolism in honey bees (Apis mellifera) at sublethal concentrations. J. Hazard. Mater. 377, 215-226. doi: 10.1016/j.jhazmat.2019.05.056

Cizelj, I., Glavan, G., Bozic, J., Oven, I., Mrak, V., and Narat, M. (2016). Prochloraz and coumaphos induce different gene expression patterns in three developmental stages of the Carniolan honey bee (Apis mellifera carnica Pollmann). Pestic. Biochem. Physiol. 128, 68-75. doi: 10.1016/j.pestbp.2015. 09.015

Dai, P., Yan, Z., Ma, S., Yang, Y., Wang, Q., Hou, C., et al. (2018). The herbicide glyphosate negatively affects midgut bacterial communities and survival of honey bee during larvae reared in vitro. J. Agric. Food Chem. 66, 7786-7793. doi: 10.1021/acs.jafc.8b02212

Decio, P., Ustaoglu, P., Roat, T. C., Malaspina, O., Devaud, J.-M., Stöger, R., et al. (2019). Acute thiamethoxam toxicity in honeybees is not enhanced by common fungicide and herbicide and lacks stress-induced changes in mRNA splicing. Sci. Rep. 9:19196. doi: 10.1038/s41598-019-55534-8

Dietrich, H., and Laber, B. (2012). "Inhibitors of cellulose biosynthesis," in Modern Crop Protection Compounds, eds W. Kramer, U. Schirmer, P. Jeschke, and M. Witschel (Weinheim: Wiley-VCH), 339-369. doi: 10.1002/9783527644 179.ch7

Elston, C., Thompson, H. M., and Walters, K. F. A. (2013). Sub-lethal effects of thiamethoxam, a neonicotinoid pesticide, and propiconazole, a DMI fungicide, on colony initiation in bumblebee (Bombus terrestris) microcolonies. Apidologie 44, 563-574. doi: 10.1007/s13592-013-0206-9

Eurostat (2018). Agri-Environmental Indicator-Consumption of Pesticides. Available online at: https://ec.europa.eu/iocont/statistics-explained/index.php/ Agri-environmental_indicator_-_consumption_of_pesticides\#Key_messages. (accessed February 16, 2020).

Fermino, F., Falco, J. R. P., and Ruvolo-Takasusuki, M. C. C. (2011). Isoenzymes and cytochemical analysis in tetragonisca angustula and tetragonisca fiebrigi after herbicide contamination. Sociobiology 58, 353-366.

Fisher, A., Coleman, C., Hoffmann, C., Fritz, B., and Rangel, J. (2017). The synergistic effects of almond protection fungicides on honey bee (Hymenoptera: I) forager survival. J. Econ. Entomol. 110, 802-808. doi: 10.1093/jee/ tox031

Garibaldi, L. A., Carvalheiro, L. G., Vaissiere, B. E., Gemmill-Herren, B., Hipolito, J., Freitas, B. M., et al. (2016). Mutually beneficial pollinator diversity and crop yield outcomes in small and large farms. Science 351, 388-391. doi: 10.1126/ science.aac7287

Hawkes, T. R. (2012). "Hydroxyphenylpyruvate dioxygenase (HPPD): the herbicide target," in Modern Crop Protection Compounds, eds W. Kramer, U. Schirmer, P. Jeschke, and M. Witschel (Weinheim: Wiley-VCH), 225-235.

Heard, M. S., Baas, J., Dorne, J.-L., Lahive, E., Robinson, A. G., Rortais, A., et al. (2017). Comparative toxicity of pesticides and environmental contaminants in bees: are honey bees a useful proxy for wild bee species? Sci. Environ. 578, 357-365. doi: 10.1016/j.scitotenv.2016.10.180

Heller, S., Joshi, N. K., Chen, J., Rajotte, E. G., Mullin, C., and Biddinger, D. J. (2020). Pollinator exposure to systemic insecticides and fungicides applied in the previous fall and pre-bloom period in apple orchards. Environ. Pollut. 265:114589. doi: 10.1016/j.envpol.2020.114589

Helmer, S. H., Kerbaol, A., Aras, P., Jumarie, C., and Boily, M. (2015). Effects of realistic doses of atrazine, metolachlor, and glyphosate on lipid peroxidation and diet-derived antioxidants in caged honey bees (Apis mellifera). Environ. Sci. Pollut. Res. 22, 8010-8021. doi: 10.1007/s11356-014-2879-7

Hinarejos, S., Abbott, J., Alix, A., Bibek, S., Cabrera, A., Joseph, T., et al. (2019). Non-Apis bee exposure workshop: industry participants'. view. Environ. Entomol. 48, 49-52. doi: 10.1093/ee/nvy138

Hladik, M. L., Vandever, M., and Smalling, K. L. (2016). Exposure of native bees foraging in an agricultural landscape to current-use pesticides. Sci. Total Environ. 542, 469-477. doi: 10.1016/j.scitotenv.2015.10.077

Hoopman, A., North, H., Rajamohan, A., and Bowsher, J. (2018). "Toxicity assessment of glyphosate on honeybee (Apis mellifera) spermatozoa," in The Society for Integrative \& Comparative Biology (SCIB) Annual Meeting 2018 (San Francisco, CA), 2-21.

Iverson, A., Hale, C., Richardson, L., Miller, O., and McArt, S. (2019). Synergistic effects of three sterol biosynthesis inhibiting fungicides on the toxicity of a pyrethroid and neonicotinoid insecticide to bumble bees. Apidologie 50, 733-744. doi: 10.1007/s13592-019-00681-0 
Jacobson, M. M., Tucker, E. M., Mathiasson, M. E., and Rehan, S. M. (2018). Decline of bumble bees in northeastern North America, with special focus on Bombus terricola. Biol. Conserv. 217, 437-445. doi: 10.1016/j.biocon.2017. 11.026

Jeschke, P. (2015). Progress of modern agricultural chemistry and future prospects. Pest Manag. Sci. 72, 433-455. doi: 10.1002/ps.4190

Jess, S., Matthews, D., Murchie, A., and Lavery, M. (2018). Pesticide use in northern ireland's arable crops from 1992-2016 and implications for future policy development. Agriculture 8:123. doi: 10.3390/agriculture8080123

Johnson, R. M., Dahlgren, L., Siegfried, B. D., and Ellis, M. D. (2013). Acaricide, fungicide and drug interactions in honey bees (Apis mellifera). PLoS One 8:e54092. doi: 10.1371/journal.pone.0054092

Johnson, R. M., Ellis, M. D., Mullin, C. A., and Frazier, M. (2010). Pesticides and honey bee toxicity - USA. Apidologie 41, 312-331. doi: 10.1051/apido/2010018

Johnson, R. M., and Percel, E. G. (2013). Effect of a fungicide and spray adjuvant on queen-rearing success in honey bees (Hymenoptera: I). J. Econ. Entomol. 106, 1952-1957. doi: 10.1603/EC13199

Jumarie, C., Aras, P., and Boily, M. (2017). Mixtures of herbicides and metals affect the redox system of honey bees. Chemosphere 168, 163-170. doi: 10.1016/j. chemosphere.2016.10.056

Klein, A.-M., Brittain, C., Hendrix, S. D., Thorp, R., Williams, N., and Kremen, C. (2012). Wild pollination services to California almond rely on semi-natural habitat: wild pollination services to California almond. J. Appl. Ecol. 49, 723732. doi: 10.1111/j.1365-2664.2012.02144.x

Kuck, K. H., Stenzel, K., and Vors, J. P. (2012). “Sterol biosynthesis inhibitors," in Modern Crop Protection Compounds, eds W. Kramer, U. Schirmer, P. Jeschke, and M. Witschel (Weinheim: Wiley-VCH), 761-805.

Ladurner, E., Bosch, J., Kemp, W. P., and Maini, S. (2005). Assessing delayed and acute toxicity of five formulated fungicides to Osmia lignaria Say and Apis mellifera. Apidologie 36, 449-460. doi: 10.1051/apido:2005032

Ladurner, E., Bosch, J., Kemp, W. P., and Maini, S. (2008). Foraging and nesting behavior of Osmia lignaria (Hymenoptera: Megachilidae) in the presence of fungicides: cage studies. J. Econ. Entomol. 101, 647-653. doi: 10.1093/jee/101. 3.647

Long, E. Y., and Krupke, C. H. (2016). Non-cultivated plants present a seasonlong route of pesticide exposure for honey bees. Nat. Commun. 7:11629. doi: 10.1038/ncomms11629

Maini, S., Medrzycki, P., and Porrini, C. (2010). The puzzle of honey bee losses: a brief review. Bull. Insectology 63, 153-160.

Malone, L. A., Scott-Dupree, C. D., Todd, J. H., and Ramankutty, P. (2007). No sub-lethal toxicity to bumblebees, Bombus terrestris, exposed to Bt-corn pollen, captan and novaluron. N. Z. J. Crop Hortic. Sci. 35, 435-439. doi: 10.1080/ 01140670709510211

Mao, W., Schuler, M. A., and Berenbaum, M. R. (2017). Disruption of quercetin metabolism by fungicide affects energy production in honey bees (Apis mellifera). Proc. Natl. Acad. Sci. U.S.A. 114, 2538-2543. doi: 10.1073/pnas. 1614864114

Meeus, I., Pisman, M., Smagghe, G., and Piot, N. (2018). Interaction effects of different drivers of wild bee decline and their influence on host-pathogen dynamics. Curr. Opin. Insect Sci. 26, 136-141. doi: 10.1016/j.cois.2018.02.007

Mengoni Goñalons, C., and Farina, W. M. (2018). Impaired associative learning after chronic exposure to pesticides in young adult honey bees. J. Exp. Biol. 221:jeb176644. doi: 10.1242/jeb.176644

Migdał, P., Roman, A., Popiela-Pleban, E., Kowalska-Góralska, M., and Opaliński, S. (2018). The impact of selected pesticides on honey bees. Polish J. Environ. Stud. 27, 787-792. doi: 10.15244/pjoes/74154

Motta, E. V. S., Raymann, K., and Moran, N. A. (2018). Glyphosate perturbs the gut microbiota of honey bees. Proc. Natl. Acad. Sci. U.S.A. 115, 10305-10310. doi: 10.1073/pnas.1803880115

Mullin, C. A., Frazier, M., Frazier, J. L., Ashcraft, S., Simonds, R., vanEngelsdorp, D., et al. (2010). High levels of miticides and agrochemicals in north american apiaries: implications for honey bee health. PLoS One 5:e9754. doi: 10.1371/ journal.pone.0009754

Nocelli, R. C. F., Soares, S. M. M., and Monquero, P. A. (2019). Effects of herbicides on the survival of the brazilian native bee Melipona scutellaris Latreille, 1811 (Hymenoptera: I). Planta Daninha 37:e019220193. doi: 10.1590/ s0100-83582019370100156
O'Brien, C., and Arathi, H. S. (2018). Bee genera, diversity and abundance in genetically modified canola fields. GM Crops Food 9, 31-38. doi: 10.1080/ 21645698.2018.1445470

Ollerton, J. (2017). Pollinator diversity: distribution, ecological function, and conservation. Annu. Rev. Ecol. Evol. Syst. 48, 353-376. doi: 10.1146/annurevecolsys-110316-022919

Patricio, G. B., Grisolia, B. B., Desuó, I. C., Montagnana, C., Brocanelli, F. G., and Gomig, E. G. (2012). The importance of bees for eggplant cultivations (Hymenoptera: I, Andrenidae, Halictidae). Sociobiology 59, 1037-1052.

Raimets, R., Karise, R., Mänd, M., Kaart, T., Ponting, S., Song, J., et al. (2018). Synergistic interactions between a variety of insecticides and an ergosterol biosynthesis inhibitor fungicide in dietary exposures of bumble bees (Bombus terrestris L.): synergistic interactions between a variety of insecticides and fungicide. Pest Manag. Sci. 74, 541-546. doi: 10.1002/ps.4756

Robinson, A., Hesketh, H., Lahive, E., Horton, A. A., Svendsen, C., Rortais, A., et al. (2017). Comparing bee species responses to chemical mixtures: common response patterns? PLoS One 12:e0176289. doi: 10.1371/journal.pone.0176289

Sgolastra, F., Arnan, X., Cabbri, R., Isani, G., Medrzycki, P., Teper, D., et al. (2018). Combined exposure to sublethal concentrations of an insecticide and a fungicide affect feeding, ovary development and longevity in a solitary bee. Proc. R. Soc. B Biol. Sci. 285:20180887. doi: 10.1098/rspb.2018. 0887

Sgolastra, F., Medrzycki, P., Bortolotti, L., Renzi, M. T., Tosi, S., Bogo, G., et al. (2017). Synergistic mortality between a neonicotinoid insecticide and an ergosterol-biosynthesis-inhibiting fungicide in three bee species: synergistic interactions between pesticides in three bee species. Pest Manag. Sci. 73, 1236 1243. doi: $10.1002 /$ ps.4449

Simon-Delso, N., Martin, G. S., Bruneau, E., Hautier, L., and Medrzycki, P. (2017). Toxicity assessment on honey bee larvae of a repeated exposition of a systemic fungicide, boscalid. Bull. Insectol. 70, 83-89.

Spurgeon, D., Hesketh, H., Lahive, E., Svendsen, C., Baas, J., Robinson, A., et al. (2016). Chronic oral lethal and sub-lethal toxicities of different binary mixtures of pesticides and contaminants in bees (Apis mellifera, Osmia bicornis and Bombus terrestris). External Sci. Rep. 13:1076E.

Stoner, K. A., and Eitzer, B. D. (2013). Using a hazard quotient to evaluate pesticide residues detected in pollen trapped from honey bees (Apis mellifera) in connecticut. PLoS One 8:e77550. doi: 10.1371/journal.pone.00 77550

Syromyatnikov, M. Y., Kokina, A. V., Lopatin, A. V., Starkov, A. A., and Popov, V. N. (2017). Evaluation of the toxicity of fungicides to flight muscle mitochondria of bumblebee (Bombus terrestris L.). Pestic. Biochem. Physiol. 135, 41-46. doi: 10.1016/j.pestbp.2016.06.007

Theodoridis, G., Lieble, R., and Zagar, C. (2012). "Protoporphyrenogen IX oxidase inhibitors," in Modern Crop Protection Compounds, eds W. Kramer, U. Schirmer, P. Jeschke, and M. Witschel (Weinheim: Wiley-VCH), 163-196.

Thompson, H. M., and Pamminger, T. (2019). Are honeybees suitable surrogates for use in pesticide risk assessment for non-Apis bees? Pest. Manag. Sci. 75, 2549-2557. doi: 10.1002/ps.5494

Tsvetkov, N., Samson-Robert, O., Sood, K., Patel, H. S., Malena, D. A., Gajiwala, P. H., et al. (2017). Chronic exposure to neonicotinoids reduces honey bee health near corn crops. Science 356, 1395-1397. doi: 10.1126/science.aam7470

Tuell, J. K., and Isaacs, R. (2009). Elevated pan traps to monitor bees in flowering crop canopies. Entomol. Exp. Appl. 131, 93-98. doi: 10.1111/j.1570-7458.2009. 00826.x

United States Environmental Protection Agency (2017). Pesticides Industry Sales Usage. Available online at: https://www.epa.gov/sites/production/files/2017-01/ documents/pesticides-industry-sales-usage-2016_0.pdf

Vázquez, D. E., Ilina, N., Pagano, E. A., Zavala, J. A., and Farina, W. M. (2018). Glyphosate affects the larval development of honey bees depending on the susceptibility of colonies. PLoS One 13:e0205074. doi: 10.1371/journal.pone. 0205074

Wade, A., Lin, C.-H., Kurkul, C., Regan, E., and Johnson, R. (2019). Combined toxicity of insecticides and fungicides applied to California almond orchards to honey bee larvae and adults. Insects 10:20. doi: 10.3390/insects100 10020

Wallner, K. (2010). Sprayed and seed dressed pesticides in pollen, nectar and honey of oilseed rape. Julius Kühn Archiv 423, 152-153. 
Walsh, T. A., and Schmitzer, P. R. (2012). "New auxin mimics and herbicides," in Modern Crop Protection Compounds, eds W. Kramer, U. Schirmer, P. Jeschke, and M. Witschel (Weinheim: Wiley VCH), 227-287.

Wcislo, W. T., and Cane, J. H. (1996). Floral resource utilization by solitary bees (Hymenoptera: Apoidea) and exploitation of their stored foods by natural enemies. Annu. Rev. Entomol. 41, 257-286. doi: 10.1146/annurev.en.41.010196. 001353

Wenger, J., Niderman, T., and Mathews, C. (2012). "Acetyl-CoA carboxylase inhibitors," in Modern Crop Protection Compounds (Weinheim: Wiley-VCH), 447-477.

Winfree, R., Reilly, J. R., Bartomeus, I., Cariveau, D. P., Williams, N. M., and Gibbs, J. (2018). Species turnover promotes the importance of bee diversity for crop pollination at regional scales. Science 359, 791-793. doi: 10.1126/science. aao2 117

Woodcock, B. A., Garratt, M. P. D., Powney, G. D., Shaw, R. F., Osborne, J. L., Soroka, J., et al. (2019). Meta-analysis reveals that pollinator functional diversity and abundance enhance crop pollination and yield. Nat. Commun, 10:1481. doi: 10.1038/s41467-019-09393-6

Zubrod, J. P., Bundschuh, M., Arts, G., Brühl, C. A., Imfeld, G., Knäbel, A., et al. (2019). Fungicides: an overlooked pesticide class? Environ. Sci. Technol. 53, 3347-3365. doi: 10.1021/acs.est.8b04392

Conflict of Interest: The authors declare that the research was conducted in the absence of any commercial or financial relationships that could be construed as a potential conflict of interest.

Copyright () 2020 Belsky and Joshi. This is an open-access article distributed under the terms of the Creative Commons Attribution License (CC BY). The use, distribution or reproduction in other forums is permitted, provided the original author(s) and the copyright owner(s) are credited and that the original publication in this journal is cited, in accordance with accepted academic practice. No use, distribution or reproduction is permitted which does not comply with these terms. 